\title{
PERBEDAAN KEJADIAN EMESIS GRAVIDARUM ANTARA IBU HAMIL YANG BEKERJA DAN TIDAK BEKERJA DI BPS ISTIJAH SURABAYA
}

\section{THE DIFFERENCE OF GRAVIDARUM EMESIS EVENTS BETWEEN PREGNANT WOMEN WHO WORK AND DO NOT WORK IN BPS ISTIJAH SURABAYA}

\author{
Zummatul Atika ${ }^{1 *}$, Nur Fajriah ${ }^{1 *}$ \\ ${ }^{1}$ Sekolah Tinggi IImu Kesehatan Surabaya Prodi D3 Kebidanan \\ email : nurfajriah@gmail.com
}

\begin{abstract}
ABSTRAK
Pendahuluan: Emesis gravidarum atau nama lainnya nausea gravidarum (NVP), atau lebih dikenal dengan istilah morning sickness adalah gejala mual - biasanya disertai muntah - yang umumnya terjadi pada awal kehamilan, biasanya pada trisemester pertama. Kondisi ini umumnya disebabkan karena meningkatnya kadar hormon estrogen. Gejala ini biasanya timbul di pagi hari dengan frekuensi yang akan menurun setiap harinya sering dengan bertambahnya usia kehamilan. Mual dan muntah terjadi 60-80\% primi gravida dan 40-60 \% multi gravida. Metode: Jenis Penelitian ini menggunakan metode analitik Observasional dan cross sectional.Populasi sebanyak 15 ibu hamil trimester I dan sampel 15 responden. Teknik pengambilan sampel dengan cara Total Sampling. Variabel Independen adalah perbedaan antara ibu hamil yang bekerja dan ibu hamil yang tidak bekerja dan variabel dependen adalah emesis gravidarum. Hasil: Berdasarkan tabel V.4. menunjukkan bahwa dari hasil tabulasi silang, menunjukan hasil bahwa dari 15 ibu hamil trimester I yang menjadi responden, dari 11 ibu hamil (73,3\%) yang mengalami mual muntah sebagian besar ibu yang bekarja yaitu 7 responden (63,6\%), sedangkan sebagian kecilnya ibu hamil yang tidak bekerja yaitu 4 responden $(36,4 \%)$ tidak bekerja. Analisis : Sehingga berdasarkan hasil uji menggunakan program SPSS 16,0 dengan menggunakan Uji Chi Square, dengan taraf signifikan derajat kemaknaan $\alpha=0,05$ didapatkan $\rho=0,485 \alpha=0,05$ maka disimpulkan bahwa H1 ditolak. Diskusi: Secara kualitatif maka terdapat perbedaan namun secara kuantitatif tidak ada perbedaan kejadian emesis gravidarum antara ibu hamil yang bekerja dan tidak bekerja di BPS Istijah Surabaya. Disarankan bagi peneliti selanjutnya agar menggunakan sampel lebih banyak untuk penelitian selanjutnya.
\end{abstract}

Kata kunci : Ibu Hamil Yang Bekerja dan Tidak Bekerja, Emesis Gravidarum 


\begin{abstract}
Introduction: Morning sickness or other names nausea gravidarum ( NVP ), or better known as morning sickness is nausea - usually accompanied by vomiting - which generally occur in early pregnancy, usually during the first trimester. This condition is usually caused by increased levels of the hormone estrogen. These symptoms usually occur in the morning with a frequency that will decrease each day often with increasing gestational age. Nausea and vomiting occurred 60-80\% primi gravida and 40-60 \% gravida multi . Methode: This type of research using the analytical observational method and cross sectional many as 15 first trimester pregnant mothers and the sample of 15 respondents. The sampling technique by means of Total Sampling. Independent variable is the difference between women who work and pregnant women who do not work and the dependent variable was morning sickness. Result: Based on the table V.4 . indicates that the cross-tabulation of the result, the results showed that of 15 pregnant women who responded to the first trimester, from 11 pregnant women ( $73.3 \%$ ) who experienced nausea vomiting most of the mothers who bekarja ie 7 respondents ( $63.6 \%$ ), while patches of pregnant women who do not work ie 4 respondents ( $36.4 \%$ ) was not working.

Analysis: So based on test results using SPSS 16.0 using Chi Square, with a significant level of significance level $=0,05$ available $\rho=0,485 \alpha=0,05$ it was concluded that $\mathrm{H} 1$ is rejected. Discussion: Qualitatively then there is a quantitative difference, but there was no difference in the incidence of morning sickness in pregnant women who work and do not work in BPS Istijah of Surabaya. It is suggested for further research in order to use more samples for further research .
\end{abstract}

\title{
Keywords : Pregnant Mother Pregnancy Work and Non Work, morning sickness
}

\section{PENDAHULUAN}

Kehamilan adalah suatu peristiwa alamiah. Pada masa ini tubuh akan banyak mengalami perubahan. Otot-otot perut beserta jaringannya meregang untuk memberi tempat kepada rahim yang akan mengembang 20 kali lebih besar dari ukuran semula (Handayani, 2010). Setengah dari wanita hamil mengalami mual muntah, walaupun kejadiannya hanya sekitar 0,5\% sampai 2\%. Kondisi ini merupakan penyebab yang paling banyak terjadi pada awal kehamilan sehingga dapat mengakibatkan kerugian bagi ibu dan janin (Maulana, 2009) 
Emesis Gravidarum adalah keluhan umum yang disampaikan pada kehamilan muda. Kehamilan menimbulkan perubahan hormonal pada wanita karena terdapat peningkatan hormone esterogen, progesterone, dan dikeluarkannya Human Chorionic Gonodothropine Plasenta. Hormon-hormon inilah yang diduga menyebabkan emesis gravidarum. Emesis Gravidarum merupakan keluhan umum yang dirasakan pada kehamilan muda berupa mual-mual dan muntah sampai usia kehamilan 4 bulan. (Manuaba, 2010). Adapun faktor yang mempengaruhi emesis gravidarum pada ibu hamil antara lain : lingkungan, pekerjaan, sikap, pola makanan yang buruk sebelum maupun pada minggu-minggu awal kehamilan, kurang tidur atau kurang istirahat dan stres dapat memperberat rasa mual dan muntah (Neil, 2010).

Menurut Departemen Kesehatan dan Kebudayaan tahun 2000 Pekerjaan adalah suatu kegiatan yang dilakukan untuk dijadikan pokok penghidupan, pekerjaan akan memberikan pengetahuan tersendiri kedalam kehidupan masyarakat dan dapat dikategorikan atas bekerja atau tidak bekerja. Apabila ibu bekerja akan menyita banyak waktu dalam pekerjaan sehingga menjadi lalai, hal tersebut akan berpengaruh pada kehamilan, seperti kurangnya perhatian terhadap kehamilan dan dapat berdampak pada kehamilannya seperti emesis gravidarum hal yang dianggap biasa - biasa saja. Dan sebaliknya dengan waktu yang tersedia maka ibu akan mempunyai banyak waktu untuk memeriksakan kehamilannya serta dapat smengetahui informasi tentang emesis gravidarum. (Depkes, 2010)

Berdasarkan data bulan Juni-Juli 2015 yang peneliti dapatkan di BPS Istijah Surabaya diketahui terdapat 25 ibu hamil. Pada bulan Juni 2015 peneliti melakukan data awal dari 10 ibu hamil yang bekerja 7 diantaranya yang mengalami mual muntah. Berdasarkan fenomena diatas maka peneliti berkeinginan untuk melakukan penelitian dengan judul "perbedaan kejadian emesis gravidarum antara ibu hamil yang bekerja dan tidak bekerja di BPS Istijah Surabaya".

\section{METODE PENELITIAN}

Penelitian ini menggunakan jenis penelitian observasional yang bersifat analitik. Observasional yaitu cara pengambilan data yang mengadakan pengamatan langsung kepada responden, penelitian untuk mencari perubahan hal-hal yang diteliti. (Notoatmodjo, 2012), Rancang bangun yang digunakan dalam penelitian ini yaitu rancang bangun cross sectional yang sering disebut transversal dimana data yang menyangkut variabel bebas atau risiko dan variabel terikat atau variabel akibat akan dikumpulkan dalam waktu yang bersamaan (Notoatmodjo, 2010). Lokasi 
penelitian ini dilakukan di BPS Istijah Surabaya yang dilakukan pada bulan Juni-Juli 2015.

Populasi dalam penelitian ini adalah seluruh ibu hamil trimester I di BPS. Istijah pada bulan Juli 2015 berjumlah 15 orang pada trimester I. Sampel yang digunakan dalam penelitian ini adalah seluruh ibu hamil trimester I yang bekerja dan tidak bekerja dengan keluhan mual muntah di BPS Istijah pada bulan Juli 2015 berjumlah 15 orang pada trimester I. Teknik pengambilan sampel dalam penelitian ini yaitu mengambil sampel dari seluruh populasi, jadi jumlah sampel adalah jumlah populasi yaitu 15 sampel dengan menggunakan teknik total sampling atau keseluruhan jumlah populasi (Notoatmodjo, 2010).

Analisa data yang dilakukan dengan menggunakan software statistical program social sciense (SPSS) versi 16 dengan uji statistik Chi Square jika $P<0.05$ dengan signifikansi 5\% ( $\propto 5 \%)$

\section{HASIL PENELITIAN DAN PEMBAHASAN}

Pelayanan kehamilan di BPS Hj. Istijah Muharli, SST., M. Mkes Kapas madya Surabaya ketika pasien datang yang pertama dilakukan seorang bidan adalah sapa, salam, senyum. Ke-2 menyiapkan lingkungan agar pasien nyaman, aman dan menjaga privacy pasien. Ke-3 menanyakan anamnesa / keluhan yang di alami pasien, buat percaya kepada bidan untuk mempermudah mendiagnosis. Ke-4 melakukan infomed consent. Ke-5 melakukan pemeriksaan kehamilan. Ke-6 memberitahu dan menjelaskan hasil pemeriksaan kepada pasien dan keluarga. Ke-7 memberikan komunikasi, informasi dan edukasi (KIE) . Ke-8 memberikan terapi. Ke-9 berikan jadwal kontrol ulang dan yang terakhir melakukan pendokumentasian.

Tabel 1. Distribusi frekuensi responden berdasarkan usia di BPS Istijah Surabaya

\begin{tabular}{ccc}
\hline Usia/ Tahun & Frekuensi & Presentase (\%) \\
\hline $16-20$ & 3 & 20 \\
$21-30$ & 10 & 66,7 \\
$31-45$ & 2 & 13,3 \\
\hline Jumlah & 15 & 100
\end{tabular}

Sumber :Data Primer Tahun 2015

Berdasarkan tabel V.1. dari 15 responden ibu hamil trimester I sebagian besar responden ibu hamil trimester I berusia 21-30 tahun sebanyak 10 orang $(66,7 \%)$ dan sebagian kecil responden ibu hamil trimester I berusia 31-45 tahun sebanyak 2 orang $(13,3 \%)$. 
Tabel 2. Distribusi frekuensi responden berdasarkan pekerjaan di BPS Istijah Surabaya

\begin{tabular}{lcc}
\hline \multicolumn{1}{c}{ Karakteristik } & Jumlah & Presentase (\%) \\
\hline Bekerja & 8 & 53,3 \\
Tidak bekerja & 7 & 46,7 \\
\hline \multicolumn{1}{c}{ Jumlah } & 15 & 100 \\
\hline
\end{tabular}

Sumber : Data Primer Tahun 2015

Berdasarkan Tabel V.2. diatas dapat diketahui bahwa dari 15 responden sebagian besar ibu hamil yang bekerja yaitu 8 responden $(53,3 \%)$ dan sebagian kecil ibu hamil yang tidak bekerja yaitu 8 responden (46,7\%).

Tabel 3. Distribusi frekuensi responden berdasarkan kejadian emesis gravidarum di BPS Istijah Surabaya

\begin{tabular}{lcc}
\hline \multicolumn{1}{c}{ Karakteristik } & Frekuensi & Presentase (\%) \\
\hline Emesis Gravidarum & 11 & 73,3 \\
Tidak Emesis & 4 & 26,7 \\
Gravidarum & & 100 \\
\hline \multicolumn{1}{c}{ Jumlah } & 15 & \\
\hline
\end{tabular}

Sumber : Data Primer Tahun 2015

Berdasarkan tabel V.3. dapat diketahui bahwa dari 15 responden, sebagian besar terjadi emesis gravidarum yaitu 11 responden (73,3\%), dan sisahnya tidak terjadi emesis gravidarum yaitu 4 responden (26,7\%).

Tabel 4.Tabulasi silang responden berdasarkan perbedaan kejadian emesis gravidarum antara ibu hamil yang bekerja dan tidak bekerja di BPS Istijah Surabaya

\begin{tabular}{|c|c|c|c|c|c|c|}
\hline \multirow{3}{*}{ Aktivitas } & \multicolumn{6}{|c|}{ Kejadian EmesisGravidarum } \\
\hline & \multicolumn{2}{|c|}{$\begin{array}{l}\text { Tidak Emesis } \\
\text { Gravidarum }\end{array}$} & \multicolumn{2}{|c|}{ Emesis Gravidarum } & \multicolumn{2}{|c|}{ Total } \\
\hline & $\mathrm{N}$ & $\%$ & $N$ & $\%$ & $N$ & $\%$ \\
\hline $\begin{array}{l}\text { Tidak } \\
\text { Bekerja }\end{array}$ & 3 & 75 & 4 & 36,4 & 7 & 46,7 \\
\hline Bekerja & 1 & 25 & 7 & 63,6 & 8 & 53,3 \\
\hline Total & 4 & 26,7 & 1 & 73,3 & 15 & 100 \\
\hline $\boldsymbol{\rho}=0,485$ & & & & & & $=0,05$ \\
\hline
\end{tabular}

Sumber : Data Primer Tahun 2015 
Berdasarkan tabel V.4. menunjukkan bahwa dari hasil tabulasi silang di atas, menunjukan hasil bahwa dari 15 ibu hamil trimester I yang menjadi responden, dari 11 ibu hamil (73,3\%) yang mengalami mual muntah sebagian besar ibu yang bekarja yaitu 7 responden (63,6\%), sedangkan sebagian kecilnya ibu hamil yang tidak bekerja yaitu 4 responden $(36,4 \%)$ tidak bekerja.

Berdasarkan hasil uji menggunakan program SPSS versi 16,0 dengan menggunakan Uji Chi Square, dengan taraf signifikan derajat kemaknaan $\alpha=0,05$ didapatkan $\rho=0,485 \alpha=0,05$ maka disimpulkan bahwa $\mathrm{H1}$ ditolak yang berarti tidak ada perbedaan kejadian emesis gravidarum antara ibu hamil yang bekerja dan tidak bekerja.

\section{Usia}

Berdasarkan hasil penelitian yang dilakukan di BPS Istijah Surabaya, menunjukkan bahwaberdasarkan tabel V.1. dapat diketahui sebagian besar responden ibu hamil trimester I berusia 21-30 tahun sebanyak 10 orang (66,6\%) dan sebagian kecil responden ibu hamil trimester I berusia 31-45 tahun sebanyak 2 orang $(13,3 \%)$.

Usia sangatlah berpengaruh pada kehamilan. Kehamilan di usia kurang dari 20 tahun bisa menimbulkan masalah, karena kondisi fisik belum 100\% siap. Kehamilan dan persalinan di usia tertsebut, meningkatkan angka kematian ibu dan janin 4-6 kali lipat dibanding wanita yang hamil dan bersaklin di usia 20-30 tahun.

Berdasarkan teori peneliti menyimpulkan bahwa usia adalah salah satu faktor resiko tinggi untuk ibu hamil. Pada deteksi dini ibu resiko tinngi Poedji Rochjati bu hamil muda $\leq 16$ tahun / ibu hamil tua $\geq 35$ tahun diberikan skor 4 yang termasuk resiko tinggi. Dari hasil penelitian secara langsung sebagian besar usia 21-30 tahun yang peneliti dapat pada ibu hamil trimester

\section{Pekerjaan}

Berdasarkan hasil penelitian yang dilakukan di BPS Istijah Surabaya, menunjukkan bahwa berdasarkan tabel V.2. dapat diketahui sebagian besar ibu hamil yang bekerja yaitu 8 responden $(53,3 \%)$ dan sebagian kecil ibu hamil yang tidak bekerja yaitu 8 responden (46,6\%). Hasil Ini juga didapat berdasarkan hasil penelitian secara langsung dari setiap ibu hamil trimester I yang bekerja maupun yang tidak bekerja, baik yang sedang mengalami mual dan muntah atau tidak mengalami mual dan muntah.

Pekerjaan adalah sebuah kegiatan aktif yang dilakukan oleh manusia. Dalam arti lain, pekerjaan digunakan untuk suatu tugas atau kerja yang menghasilkan 
sebuah karya bernilai imbalan dalam bentukuang bagi seseorang. Dalam pembicaraan sehari-hari istilah pekerjaan dianggap sama dengan profesi.

Menurut peneliti, Pekerjaan adalah salah satu pokok penting bagi kehidupan, karena pekerjaan dapat meningkatkan kualitas bagi setiap manusia. Baik dari segi ekonomi, pengetahuan/wawasan, pengalaman dan sebagainya.

\section{Emesis Gravidarum}

Berdasarkan hasil penelitian yang dilakukan di BPS Istijah Surabaya, menunjukkan bahwaberdasarkan tabel V.3. dapat diketahui bahwa dari 15 responden, sebagian besar terjadi emesis gravidarum yaitu 11 responden (73,3\%), dan sisahnya tidak terjadi emesis gravidarum yaitu 4 responden $(26,6 \%)$.

Dalam penelitian ini ada sebuah teori yang mengasumsi bahwa penyebab terjadinya emesis gravidarum sampai saat ini tidak dapat diketahui secara pasti. Ada yang mengatakan bahwa perasaan mual disebabkan oleh karena meningkatnya kadar hormon estrogen dan HCG (Human Chorionic Gonadotrophin) dalam serum (Manuaba, 2010). Adapun faktor yang mempengaruhi emesis gravidarum pada ibu hamil antara lain : lingkungan, pekerjaan, sikap, pola makanan yang buruk sebelum maupun pada minggu-minggu awal kehamilan, kurang tidur atau kurang istirahat dan stres dapat memperberat rasa mual dan muntah (Neil, 2010).

Berdasarkan data yang diperoleh dan didukung oleh teori para ahli, hampir dapat disimpulkan bahwa emesis gravidarum dengan istilah lain morning sickness adalah keluhan umum yang disampaikan pada kehamilan muda, biasanya pada ibu hamil trimester I yang disebabkan karena meningkatnya hormon estrogen. Gejala ini biasanya timbul di pagi hari, gejala ini akan hilang dengan bertambahnya usia kehamilan namun dapat juga menjadi semakin parah sehingga menjadi hiperemesis gravidarum.

\section{Perbedaan Kejadian Emesis Gravidarum Antara Ibu hamil Yang Bekerja dan Tidak Bekerja.}

Berdasarkan tabel V.4. menunjukkan bahwa dari hasil tabulasi silang, menunjukan hasil bahwa dari 15 ibu hamil trimester I yang menjadi responden, dari 11 ibu hamil (73,3\%) yang mengalami mual muntah sebagian besar ibu yang bekarja yaitu 7 responden (63,6\%), sedangkan sebagian kecilnya ibu hamil yang tidak bekerja yaitu 4 responden (36,4\%) tidak bekerja. Sehingga berdasarkan hasil uji menggunakan program SPSS 16,0 dengan menggunakan Uji Chi Square, dengan taraf signifikan derajat kemaknaan $\alpha=0,05$ didapatkan $\rho=0,485 \alpha=0,05$ maka disimpulkan bahwa $\mathrm{H} 1$ ditolak yang berarti tidak ada perbedaan kejadian emesis gravidarum antara ibu hamil yang bekerja dan tidak bekerja. 
Namun dalam teori dapat disimpulkan tidak semua ibu hamil yang bekerja akan mengalami emesis gravidarum karena pekerjaan adalah suatu kegiatan yang dilakukan untuk dijadikan pokok penghidupan, pekerjaan akan memberikan pengetahuan tersendiri kedalam kehidupan masyarakat dan dapat dikategorikan atas bekerja atau tidak bekerja. Namun, Ada juga ibu hamil bekerja akan menyita banyak waktu dalam pekerjaan sehingga menjadi lalai, hal tersebut akan berpengaruh pada kehamilan, seperti kurangnya perhatian terhadap kehamilan dan dapat berdampak pada kehamilannya seperti emesis gravidarum hal yang dianggap biasa - biasa saja. Dan sebaliknya dengan waktu yang tersedia maka ibu akan mempunyai banyak waktu untuk memeriksakan kehamilannya serta dapat smengetahui informasi tentang emesis gravidarum. (Departemen kesehatan dan kebudayaan, 2000 ).

Sehingga berdasarkan fakta yang peneliti dapat dan berdasarkan teori yang menjadi patokan, maka ditemukan dua hasil yang penieliti dapat. Secara kualitatif ditemukan perbedaan kejadian emesis gravidarum antara ibu hamil yang bekerja dan tidak bekerja dengan presentase sebagian besar ibu yang bekerja mengalami emesis gravidarum 63,6 \% sedangkan sebagian kecil ibu yang tidak bekerja mengalami emesis gravidarum 36,4 \%. Sedangkan secara kuantitatif dengan perhitungan SPSS versi 16,0 H1 ditolak maka dinyatakan tidak ada perbedaan kejadian emesis gravidarum antara ibu hamil yang bekerja dan tidak bekerja karena peneliti hanya menemukan samping 15 responden pada trimester I dimana dalam perhitungan SPSS 16,0 dengan menggunakan Uji Chi Square, dengan taraf signifikan derajat kemaknaan $\alpha=0,05$ didapatkan $\rho=0,485 \alpha=0,05$. Dari penelitian ini diharapkan untuk peneliti selanjutnya agar menggunakan sampel lebih banyak untuk memenuhi kriteria SPSS dan mendapatkan hasil sesuai yang diharapkan pada penelitian selanjutnya.

\section{SIMPULAN}

Berdasarkan hasil penelitian yang dilakukan untuk mengetahui adanya Ada perbedaan antara ibu hamil yang bekerja dan ibu hamil yang tidak bekerja dengan kejadian emesis gravidarum di BPS Istijah Surabaya pada tanggal 10-26 Juli 2015 dapat disimpulkan bahwa:

1. Sebagian besar ibu yang bekerja mengalami emesis gravidarum pada trimester I yaitu $63,6 \%$

2. Sebagian kecil ibu yang tidak bekerja mengalami emesis gravidarum pada trimester I yaitu 36,4\% 
3. Secara kualitatif maka terdapat perbedaan namun secara kuantitatif tidak ada perbedaan kejadian emesis gravidarum antara ibu hamil yang bekerja dan tidak bekerja di BPS Hj. Istijah Muharli, SST., M. Mkes Kapas madya Surabaya.

\section{DAFTAR PUSTAKA}

1 Atmowiloto, Arswendo. 2009. Dua Ibu. Jakarta: gramedia Pustaka Utama.

2 Asrinah, dkk. 2010. Asuhan Kebidanan Masa Kehamilan. Yogyakarta: Graha Ilmu

3 Canningham. 2013. Obsetri williams. Jakarta: EGC

4 Curtis, Glade. 2000. Kehamilan di Atas Usia 30. Yasmin, Alih Bahasa. Jakarta: Arcan

5 Depkes RI Provinsi Jawa Timur. 2010. Profil Kesehatan Provinsi Jawa Timur Tahun 2013. Surabaya

6 Dinkes Surabaya. 2011. Profil Kesehatan Wilayah Surabaya Tahun 2011. Surabaya

7 Februanti, Sofia. 2013. Keperawatan Maternitas 5: Konsep dan Asuhan Keperawatan Ibu Hamil normal dan komplikasi. Jakarta

8 Handayani, Fitri. 2010. Faktor-faktor Ibu Hamil Yang Berhubungan Dengan Antenatal Care. Jakarta: EGC

9 Hanni, Umi, dkk. 2011. Asukan Kehamilan Pada Kehamilan Fisiologi. Jakarta: Salemba Medika

10 Hartiningtiyaswati, Setiya, Dkk. 2013. Asuhan Kehamilan Berbasis Bukti. Jakarta: Sagung Seto

11 Kepmenakertrans. 2004. Ketentuan Struktur dan Skala Upah. Jakarta

12 Lestari. 2009. Ilmu Kebidanan: Kehamilan. Jakarta: Pusat Perbukuan

13 Manuaba, IBG, dkk. 2010. Ilmu Kebidanan Penyakit Kandungan dan KB. Jakarta: EGC

14 Maryunani, AMK. 2010. Ilmu Kesehatan Anak Dalam Kebidanan. Jakarta: TIM

15 Maulana, M. 2009. Cara Cerdas Menghadapi Kehamilan dan Mengasuh Bayi. Jokjakarta: Kata Hati

16 Neil, W. 2010. The Complete Handbook of Pregnancy. Alih Bahasa, Soekardjo. Jakarta: Dian Rakyat

17 Nurdiansyah, Nia. 2011. Buku Pengantar Ibu dan Bayi. Jakarta: Bukune

18 Nursalam. 2010. Metodologi Penelitian Ilmu Keperawatan: Pendekatan Praktis. Jakarta: salemba medika.

19 Notoatmodjo, Soekidjo. 2010. Metodologi Penelitian Kesehatan. Jakarta: Rineka Cipta.

20 Notoatmodjo, Soekidjo. 2012. Metodologi Penelitian Kesehatan. Jakarta: Rineka Cipta. 

e-ISSN:

21 Notoatmodjo, Soekidjo. 2013. Metodologi Penelitian Kesehatan. Jakarta: Rineka Cipta.

22 Sufriyanto. 2009. Metodologi Penelitian. Jakarta: Rineka Cipta

23 Undang-undang Dasar RI. 2003. Ketenagakerjaan Tahun 2003. Jakarta

24 Undang-undang Dasar RI. 2003. Perbendaharaan Negara Tahun 2003. Jakarta

25 Varney, dkk. 2010.Buku Saku Asuhan Kebidanan Volume II. Jakarta: EGC

26 Wiknjosastro, Hanifa. 2007. Ilmu Kebidanan. Jakarta: Yayasan Bina Pustaka Sarwono Prawirohardjo

27 Winkjosastro, Hanifa. 2010. Ilmu Bedah Kebidanan. Jakarta: PT. Bina Pustaka sarwono prawiroharjo

28 Wulanda. 2011. Biologi Reproduksi. Jakarta: Salemba Medika

29 Yuni, Kusmiati, dkk. 2009. Perawatan ibu hamil (Asuhan Ibu hamil). Yogyakarta 